\title{
Ensuring the Economic Sustainability of the Railway National Company in a Globalizing World Economy
}

\author{
Liliya Kazanskaya ${ }^{1}$, Natalya Drivolskaya ${ }^{2 *}$ \\ ${ }^{1}$ Emperor Alexander I Petersburg State Transport University, Russia \\ ${ }^{2}$ Emperor Alexander I Petersburg State Transport University, Russia
}

\begin{abstract}
The railway industry of the Republic of Uzbekistan is currently an emerging market for transport services that integrates into the global economy, primarily in the Asian space. This is explained by the fact that the Republic of Uzbekistan occupies a strategic geographical position in Central Asia and is the center of the region's geopolitical development, the main transit corridors connecting the North and South, East and West of the continent pass through the territory of the Republic of Uzbekistan [1]. When organizing both freight and passenger rail traffic, the issues of ensuring their safety should be considered taking into account the parameters of economic sustainability, which is still not given due attention. Based on the analysis of the indicators and the assessment of traffic safety in JSC "Uzbekistan Temir Yollari", the authors identified such planning steps as analyzing traffic safety indicators and identifying problems, analyzing the causes of the problems identified, forming the idea of a goal, checking the achievement of a goal, development of options for activities to achieve goals. For each stage, based on the methods of correlation, regression and factor analysis, algorithms for their implementation have been developed. A concept of measures has been developed with the aim of increasing the economic efficiency of traffic safety management depending on the method of control. The authors believe that the implementation of the proposed recommendations for decision-making on road safety is a comprehensive preventive measure to ensure a guaranteed level of economic security in the developing market of Uzbekistan.
\end{abstract}

\section{Problems of traffic safety management in the railway company of the Republic of Uzbekistan}

The competitive transportation market in the process of structural reform of the railway industry was formed during the period of strategic problems of railway transport $[2,3]$. This condition led to the construction of an inefficient market model [4]. Unresolved industry problems and new threats identified in the tasks of ensuring traffic safety created risks of lowering the economic stability of the railway company and the emergence of environmental

\footnotetext{
${ }^{*}$ Corresponding author: natabur76@ mail.ru
} 
problems $[5,6]$. In this regard, the task of building a traffic safety management system taking into account the economic sustainability of the railway company is becoming relevant [7].

Since transport services must be safe for passengers and cargo owners, the state must determine the acceptable value of the risk of loss of life and health by the passenger, as well as the risk of loss of cargo by the cargo owner during transportation along certain routes, i.e. set regulatory values [8]. However, at present the state has not established normative values of risk indicators, therefore it is impossible to formulate strictly state-justified requirements for the parameters and functional characteristics of technical equipment and professional characteristics of the railway personnel of "Uzbekistan Temir Yollari” JSC (UTY).

If at the state level standard values of indicators are established, and they turn out to be higher than optimal, to achieve them, UTY will increase traffic safety costs and the question arises of their compensation. Partially they must be compensated by the state, for example, through transportation tariffs, and partially by UTY. The participation of UTY in increasing traffic safety will stimulate its search for the most economical methods to improve safety.

If at the state level standard values of indicators are established, and they turn out to be higher than optimal, then to achieve them UTY will increase the cost of traffic safety and the question arises of their compensation. Partially they must be compensated by the state, for example, through transportation tariffs, and partially by UTY. The participation of UTY in increasing traffic safety will stimulate its search for the most economical methods to improve safety.

It should be borne in mind that the state policy of Uzbekistan in the field of traffic safety should be based on an assessment of the real economic opportunities of UTY, taking into account scientific and technological achievements. Otherwise, increased requirements for traffic safety may lead to bankruptcy of the company. Without knowledge of normative safety indicators for the functioning of technical equipment, it is fundamentally impossible to certify them in terms of traffic safety. Certification is a comparison of the actual value of the Traffic Safety indicator with a pre-set (normative) or actual parameters of a technical tool with a preset parameters, which provide a predetermined safety indicator for the functioning of a technical tool. At present, normative safety indicators for the functioning of technical means have not been established, therefore, technical means are certified in the best case on the basis of common sense, and in the worst - completely arbitrary.

It is impossible to effectively manage traffic safety without reliable data on the probability indicators (frequency) of the occurrence of dangerous destabilizing factors [8]. The applied system of their identification does not provide the necessary reliability of the information. It can be achieved by automating the collection of information about dangerous destabilizing factors and the causes of their occurrence, as well as increasing the responsibility of personnel collecting and transmitting information. The development of methods and means of increasing the completeness and reliability of information about dangerous technical equipment failures and dangerous personnel errors, as well as the reasons for their occurrence, is the most important direction for improving the functional properties of traffic safety control systems [5].

Analysis of traffic safety at UTY JSC allowed us to determine the reasons for the transition of the traffic to a dangerous state and, accordingly, identify with a certain probability the most frequent ones. For example, about half of all transitions of train traffic to a dangerous state are caused by violations of the maintenance and repair technologies of the track, about a third are caused by violations of the maintenance and repair technologies of cars, primarily their mechanical parts due to low technological discipline and insufficient professional level of personnel. Dangerous failures also occur in the form of excess deviations of the geometric 
parameters of the track due to a violation of the technological operations of the current track maintenance.

Low technological discipline and insufficient professional level of personnel engaged in operational traffic management are the causes of crashes, accidents and other traffic safety violations.

\section{Defining the functions of a traffic safety management system}

Analysis of the data of UTY JSC allows us to determine the main strategic direction of work to improve traffic safety. This is a decrease in the probability of technology violations of the current content of the path [6].

At present, the function of determining the actual values of the listed probabilistic indicators of traffic safety and risks is not performed, and as a result, their compliance with regulatory values is not controlled [7].

The next important function of the traffic safety management system is, as already noted, the determination of the effectiveness of safety improvements. To assess the economic efficiency of a specific measure to improve traffic safety, it is advisable to use the indicator of net present value (integral effect) at a constant discount rate and basic price costs.

The economic efficiency indicator should be used to assess the effectiveness of measures to improve traffic safety from the point of view of the interests of both the state and UTY JSC. In the first case, it is necessary to take into account the costs and damage of all individuals involved in the crash, accident (passengers, personnel of transport systems, the population), and all legal entities (state, companies with various forms of ownership). In the second case, only the costs and damage incurred by UTY. At the same time, one-time and current expenses of UTY JSC without a re-invoice must be included in the cost structure.

If the quantitative assessment of the damage risks of potential failures is difficult due to the lack of information on the costs of their recovery, at the first stage, the economic damage can be estimated by an expert method [10]. The maximum economic damage averaged by experts is determined by the formula

$$
C_{i}=\sum_{j=1}^{R_{i j}} P_{i j} C_{i j}
$$

Where $\mathrm{i}$ is the specific failure number, $i=1,2,3, \ldots$; - number of the type of risk, $j=1,2,3, \ldots ; P_{i j}$ - probability of occurrence of the $\mathrm{j}$-th number of potential risk for the ith failure; $C_{i j}$ - economic damage from the $\mathrm{j}$-th number of the type of risk for the $\mathrm{i}$-th failure.

To take into account the influence of the human factor on traffic safety, you can use the point method, which is based on an analysis of the types of consequences and the criticality of failures. Then the significance (criticality) of the human factor in the overall traffic safety is determined by the formula

$$
Z=B_{1} \cdot B_{2} \cdot B_{3}
$$

Where $B_{1}, B_{2}, B_{3}$ - are the scores of the frequency, significance and probability of the influence of the human factor on traffic safety, respectively. An assessment of the total damage from traffic safety mismatch can also be carried out on the ratios between investments and operating costs (Fig. 1). It follows from the cost triangle that with an increase in investments aimed at increasing the level of traffic safety with a 
subsequent reduction in the number of dangerous failures, operating costs decrease, i.e., with an increase in the investment area, the area of operating costs decreases.

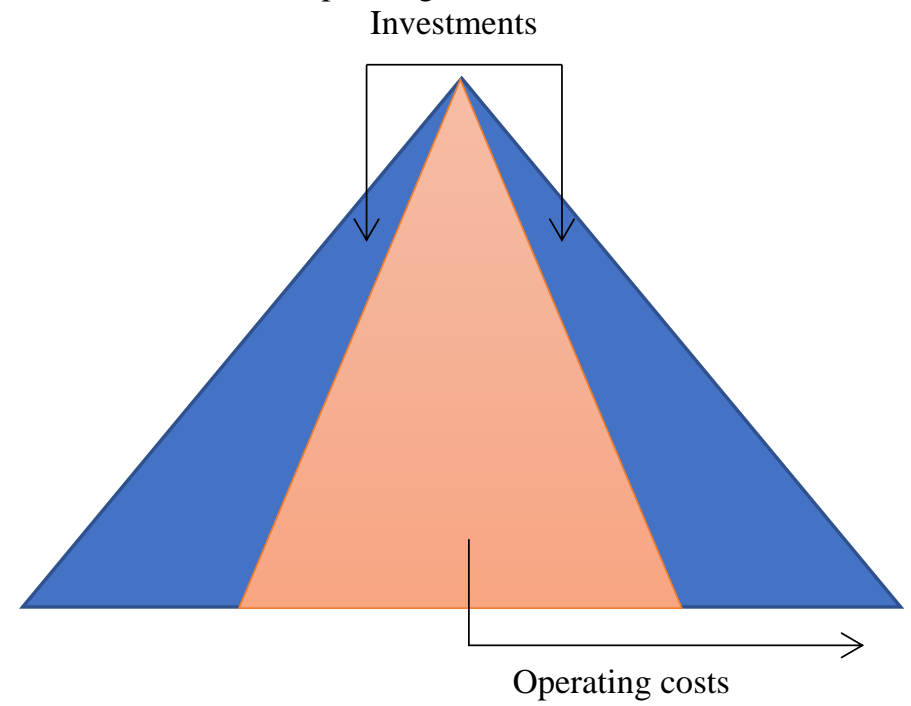

Fig. 1. The relationship of operating costs and investments aimed at improving the level of traffic safety

In this case, to improve traffic safety while reducing risks, you can approach from several sides:

- for a certain amount of investment and a known cost of influencing factors, it is possible to predict the level of traffic safety, and a further increase in investment to prevent the action of certain factors allows you to get the maximum effect even in limited conditions;

- with an increase in labor productivity on the railway by a certain amount with a constant level of investment, it is possible to calculate and predict the level of traffic safety, as well as adjust this level by increasing investment;

- with an insufficient level of investment to ensure the necessary level of traffic safety and with an increase in labor productivity on the railway, it is necessary to build additional feedback in the management structure to provide additional control with the development of control actions and aimed at lowering operational performance [9].

\section{Development of proposals for the construction of a traffic safety management system}

Guaranteed provision of a given level of safety of life and health of people, nature, material values and technical complexes during the implementation of the transportation process at UTY at all its stages, as well as a specified level of reliability of the transportation process, is the main thing in the social policy of Uzbekistan.

Basic principles when building a traffic safety management system:

- determination of acceptable levels of risks and norms of indicators of traffic safety;

- monitoring of traffic safety, implementation of management decision support systems to predict the reliability of transportation and prevent security breaches;

- updating the technical and technological base, improving the reliability of technical means, improving information technologies in the field of traffic safety; 
- assessment of the economic efficiency of investment projects in the field of traffic safety and the reliability of the transportation process, taking into account the likelihood of incidents, events and failures, possible direct and indirect losses, and lost profits;

- bilateral exchange of information related to traffic safety issues both vertically and horizontally;

- the formation of a safety culture, the involvement of personnel in solving traffic safety problems, the control of professional knowledge in the field of traffic safety;

- improving the procedures for investigating traffic accidents;

- audit and audit of the traffic safety management system.

The transition to new operating conditions (a single business entity in the form of a jointstock company (UTY JSC)), negative dynamics of operating results, depreciation of fixed assets, extraordinary geographical diversification of the company and its structural divisions, the specifics of creating the final product and other factors have intensified the management's work improvement (through reorganization) of the internal management system [11].

Conversion Goals:

- improving the efficiency of the backbone elements, which should be understood as the totality of business units, as well as their units;

- increasing investment attractiveness;

- development of competitiveness [12-14] of UTY JSC in the market of transport services.

Organizational changes will help create conditions for decentralization, lead to faster decision-making and to improve their quality, to the implementation of initiatives coming from levels familiar with specific problems, to increase business activity and responsibility of managers of all levels of management, etc. In this case, there may be a double subordination of linear enterprises and a violation of a single initial principle, which provokes the development of the duality of the opinions of the team chain, disagreements and the risk of possible conflict situations, so it will take much more time to agree and make decisions. 2.

The traffic safety management system at UTY may have a control structure shown in Fig.

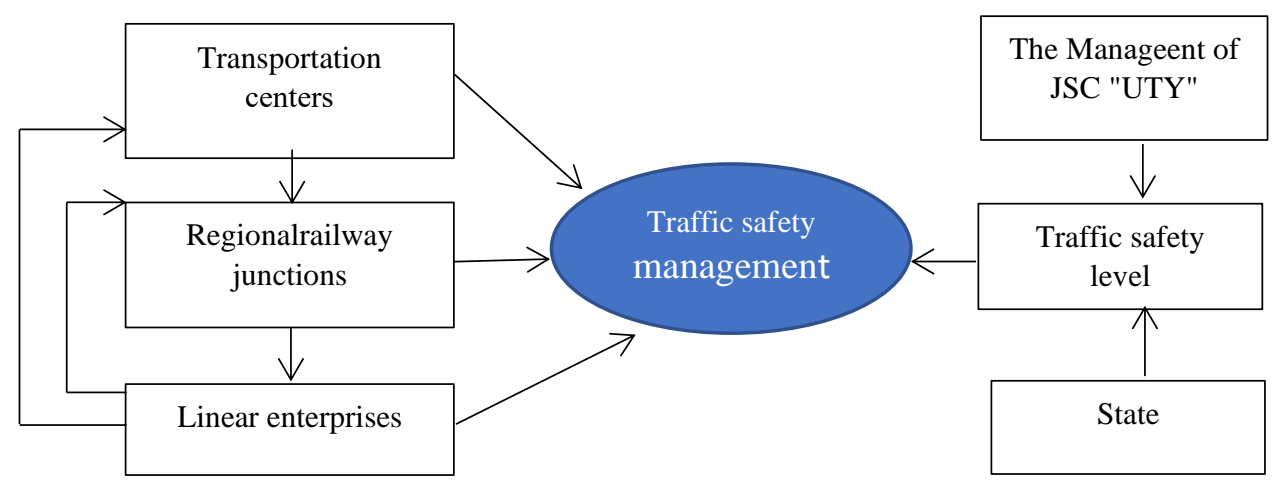

Fig. 2. The proposed block diagram of the relationship of structural units of UTY JSC in the management of traffic safety with feedback

The given structural diagram of the relationship between the structural units of UTY JSC differs from the current one in that it contains feedback between the traffic safety management links. In addition, the functions associated with monitoring the necessary level of traffic safety are performed by both the company's board and the state [15-18]. 
Introduction to the traffic safety management system of the risk indicator will allow you to see the various components in one dimension and carry out safety prevention planning at a certain level. With the introduction of normative values of traffic safety indicators, it will be possible to carry out comprehensive measures to prevent emergency situations and technical equipment failures at an early stage, to design safety at the planning stage, as well as justify and change the standards for technical equipment, and regulate the human factor impact when performing personnel work. Planning in solving everyday problems of the railway industry should be based on the analysis of specific cases, conditions, conditions, strategic goals, and statistics to identify weak links in possible failures [19].

\section{Conclusion}

When building a traffic safety management system, it is necessary to take into account the number of traffic safety violations depending on the productivity of workers, the volume of investments and operating costs. This model allows you to distribute and ensure rational financing of the industry in order to achieve the required level of security. The forecast can be made both for the entire network as a whole, and for individual railway sections. In addition, it is possible to optimize operating expenses and investment plans to increase the economic stability of UTY, taking into account traffic safety factors [20,21].

The developed forecasting model is dynamic in nature, i.e., with an increase in the source data array, the forecast for subsequent periods is given with a greater degree of reliability [22].

\section{References}

1. N. M. Ibragimova, Ekonomika i matematiceskie metody-economics and mathematical methods, 53 (4), 75-88(2017)

2. M. Nadanyiova, The Customer Satisfaction with Services Railway Company Cargo Slovakia as a Factor of Competitiveness. In 18th International Conference on Transport Means (Kaunas, Lithuania, 120-124, 2014)

3. A. Krizanova, The current possition and perspecives of the integrated transport systems in Slovak republic. Eksploatacja i niezawodnosc - maintenance and reliability, 4, 25-27 (2008)

4. L. Kazanskaya, E. Palkina, 16th International Scientific Conference on Globalization and its Socio-Economic Consequences Местоположение: Rajecke Teplice, SLOVAKIA , (2016)

5. L.F. Kazanskaya, 21st Century Initiatives, 4, 35-39(2015)

6. L.F. Kazanskaya, V.M. Artimovich, Sh.Sh. Rizakulov, Scientific notes of the International Banking Institute, 22, 115-130(2017)

7. N.A. Zhuravleva, Economics of Railways, 9, 23-30(2012)

8. S. Hajduk, Efficiency evaluation of urban transport using the DEA method, Equilibrium. Quarterly Journal of Economics and Economic Policy 13, 141-157 (2018)

9. M. Lyakina, W. Heaphy, V. Konecny, T. Kliestik, Algorithmic governance and technological guidance of connected and autonomous vehicle use: Regulatory policies, traffic liability rules, and ethical dilemmas, Contemporary Readings in Law and Social Justice 11, 15-21 (2019) 
10. Sh.Sh. Rizakulov, Transport logistics, multimodal transportation: problems and solutions. Tashkent, Uzbekistan, 28-30, (2014)

11. I. Guliy, T Satsuk, S. Tatarintseva, Indo american journal of pharmaceutical sciences, 6 ( 3 ), 6293(2019).

12. RS Kaplan, DP Norton, 74( 1 ), 75 (1996).

13. V. V Bobrova, L. Yu. Berezhnaya, Proceedings of the 1st international scientific conference modern management trends and the digital economy: from regional development to global economic growth, 81, 174 (2019)

14. V. Spitsin, A. Mikhalchuk, I. Pavlova, L. Spitsina, Labor indicators and manufacturing companies ownership patterns in Russia and its regions: Results of quantitative analysis, Oeconomia Copernicana 9, 261-285 (2018)

15. E. H. C. Choi, R.Taib, Y. Shi, Iet intelligent transport systems, 1(1), 27(2007)

16. N.A. Zhuravleva, E. Nica, P. Durana, Sustainable smart cities: Networked digital technologies, cognitive big data analytics, and information technology-driven economy, Geopolitics, History, and International Relations 11, 41-47 (2019)

17. D. Lapple, F .Thorne, Journal of agricultural economics, 70 (1), 178 (2019)

18. A. Mashokhida, A. A Khabibovich, P Palka, Journal of comp, 10(1), 73 (2018)

19. A.D. Meilă, Sustainable urban mobility in the sharing economy: Digital platforms, collaborative governance, and innovative transportation, Contemporary Readings in Law and Social Justice 10, 130-136 (2018)

20. S. Djabbarov, Transport problems, 11 (4), 103 (2016)

21. N. Aripov, R. Aliyev,; D. Baratov, 9th International Scientific Conference on Transbaltica, Vilnius Gediminas Tech Univ, Vilnius, LITHUANIA, (2015)

22. G. Unal, Journal of mehmet akif ersoy university economics and administrative sciences faculty, 5(3), 519 (2018) 